\title{
Retreat, Submission, and the Private Use of Force
}

\author{
Mark Dsouza* \\ *This is a version of the accepted manuscript. The final publication is available at \\ http://ojls.oxfordjournals.org/content/early/2015/04/15/ojls.gqv016.abstract*
}

\begin{abstract}
Different jurisdictions disagree on whether a person facing an illegitimate threat is ever required to retreat in the face of it or to submit to it, rather than using force in defence. Those that have attempted to identify the principled position on this issue also disagree about

(a) the philosophical source (if any) of the duty to retreat;

(b) the interests that may privately be defended; and

(c) the point of time at which private force becomes available to a defender.

I address these disputes by suggesting that rules requiring retreat or submission must be limitations on private force that flow from the state's monopoly of legitimate force within its jurisdiction. I argue that these limitations on private force operate at two stages. The first stage limitations restrict 'in-principle' access to private force to cases in which the threat cannot be avoided non-forcefully, and the second stage limitations ensure that the force privately deployed does not exceed the force that the state could itself have legitimately deployed. Next, I examine whether certain interests often taken to be privately defensible ought to be treated as such. Finally, I describe the model of retreat and submission that follows from the ideas canvassed.
\end{abstract}

Keywords - self-defence, monopoly of force, honour, retreat

\section{Introduction}

Different jurisdictions have different rules about whether a person is required to avoid conflict, if

* Lecturer in Law, School of Law and Social Justice, University of Liverpool. Email: mdsouza@ liverpool.ac.uk Drafts of this paper were presented at the Cambridge Criminal Law Theory Group Seminar Series and the University of Liverpool Law Research Seminar Series. I am grateful for the insightful comments, suggestions, and criticisms of those that attended. My particular thanks to James Edwards, Matt Dyson, Findlay Stark, Johanna Göhler, Matt Gibson, Antje $\mathrm{du}$ Bois-Pedain, and the anonymous referees. Part of the research for this paper was carried out during my $\mathrm{PhD}$ studies at the University of Cambridge, and I am grateful to the Rajiv Gandhi (UK) Foundation for awarding me a Cambridge International Scholarship to fund those studies. 
possible, instead of using defensive force. Some jurisdictions, primarily in the United States, do not expect retreat in the face of certain attack, either generally, or, from specified places. ${ }^{1}$ Others, like England and Wales, treat efforts to retreat as evidence that the use of defensive force was reasonable. ${ }^{2}$ Still others, like Scotland, permit the use of force in defence only if the agent had no reasonable means of escape or retreat. ${ }^{3}$ In each of these jurisdictions, the posited law is implicitly or explicitly taken to be justified on the basis of underlying philosophical principle rather mere formal rules of legislative authority and form. However, the proper statement of this underlying principle is also the subject of intense academic dispute. In particular, theorists disagree about

(a) the philosophical source (if any) of a person's duty to retreat;

(b) the interests that may privately be defended; and

(c) the point of time at which private force becomes available to a defender.

In this paper, I address these disputes while examining the principles underpinning the legitimate private use of force. In Section 2, I examine how the state's monopoly of force shapes a subject's private access to force, and suggest refinements in how we classify and understand the limitations usually imposed on such force. Specifically, I propose that these conditions be classified

\footnotetext{
${ }^{1}$ For instance North Carolina General Statutes, §14-51.2, 14-51.3; Florida Statutes, §776.012, 776.013, 776.031, 776.032; Illinois Criminal Code of 1961, Ss.7-1, 7-2, 7-3; Kentucky Revised Statutes, §503.080. In German law too, the traditional principle is that 'right must never yield to wrong', and therefore a person need never retreat in the face of a wrongful threat. This rule is moderated under special conditions by socio-ethical constraints requiring restraint, and perhaps also a limited retreat, when the aggressor is not culpable, or when the defender has given rise to the need for self-defence through her own unlawful acts. See George P Fletcher, Rethinking Criminal Law (Little, Brown and Company1978) at 865, and Mordechai Kremnitzer, 'Proportionality and the Psychotic Aggressor: Another View' (1983) 18(2) Israel Law Review 178, 207. See also Albin Eser, 'Justification and Excuse' (1976) 24 American Journal of Comparative Law 621, 632.

${ }^{2}$ Criminal Justice and Immigration Act 2008, s76(6A). See also $R v$ Julien [1969] 1 WLR 839; $R v$ Bird (1985) 81 CrAppR 110; Duffy v Chief Constable [2007] EWHC 3169 (Admin).

3 McBrearty v HM Advocate 1999 SLT 1333.
} 
in terms of whether they govern in-principle access to private force, or the subsequent deployment thereof. In Section 3, I examine three interests often taken to be privately defensible, viz. Hohfeldian liberties, the social-legal order, and honour, and argue that they are either not privately defensible, or only sometimes privately defensible. In Section 4, I critique existing theories of retreat in the criminal law, and describe an alternative composite explanation of retreat and submission that flows from the arguments made herein. I argue that the 'duty to retreat' flows from the availability of alternatives to the private use of force, and that in principle, a person may privately use force when faced with a present and unavoidable threat to defensible interests. I further argue that the 'duty to submit' stems from the unavailability of effective defensive responses that are not disproportionately more serious than the threat being repelled.

Although I refer to arguments and examples drawn primarily from English and American law, I will not attempt to justify the doctrinal law of any jurisdiction. Furthermore, in order to keep this paper manageable in scope, I will assume throughout that there is no gap between the agent's perception of situational facts, a reasonable perception of those facts, and the objective facts. An argument on how, if at all, this paper's account of retreat and submission in private defence must be modified to account for any such gap that appears, must await another day.

\section{Private Access to Force and the State's Monopoly of Force}

Every modern state assumes the role of the primary enforcer of rights, and exercises ${ }^{4}$ a monopoly over the legitimate use of force ('MLF') within its jurisdiction, such that no individual subject to its jurisdiction is ordinarily permitted to use force. ${ }^{5}$ It stakes out the boundaries of MLF by declaring

\footnotetext{
4 To clarify, I need not, and do not take any stand as to the source of the state's MLF here. Even if the state receives its MLF from its citizens, on any plausible account this entrustment cannot (at least in effect) be revocable. Even if such a revocation is theoretically possible (say by way of a revolution), that possibility can be discounted in the ordinary course of political affairs.

5 This idea traces back to Max Weber's famous essay titled 'Politics as a Vocation' and is almost universally accepted
} 
that certain uses of force are presumptively criminal, inasmuch as criminal liability will follow from them unless some defence is offered. Some uses of force fall outside the boundaries of MLF - for instance consensual force is not presumptively criminal, because in principle, valid consent negates the actus reus of an offence. ${ }^{6}$ Similarly, the state's MLF also excludes most instances of purely private force against one's own entitlements or property, and arguably, the limited use of force permitted in parental chastisement. I will not dwell on instances of force that are considered external to MLF here. Instead, I focus on instances of private force that lie within the ordinary bounds of MLF, but are nevertheless permitted by the state as exceptions to MLF. Examples include instances of force used in:

(a) the justified private defence of person or property; ${ }^{7}$

(b) the prevention of crime; and

(c) making a citizen's arrest.

The 'duty to retreat' is generally envisioned as something to be performed by a person facing a threat (D) before she is permitted to use force in justified private defence. In other words, retreat is understood as a precondition for access to exception (a) to MLF. Therefore, we must start with a closer examination of MLF.

as a foundational principle of state amongst modern liberal states. See also Robert Nozick, Anarchy, State, and Utopia (Basic Books 1974) at 23, 117-8.

${ }^{6}$ R Antony Duff, Answering for Crime (Hart 2007), at 208-10; Mark Dsouza 'Undermining Prima Facie Consent in the Criminal Law' (2014) 33 Law and Philosophy 489, 494-7; Mark Dsouza, 'The Power to Consent and the Criminal Law' (2013) University of Cambridge Faculty of Law Research Paper 9/2013, <http://ssrn.com/abstract=2225267> accessed 31 July 2014, at 15 .

7 See in this regard Fletcher (n1) at 867, who explains that it is implicit in the modern Anglo-American conception of defensive force that access to such force derives from the state. See also Whitley R P Kaufman, 'Self-Defense, Imminence, and the Battered Woman' (2007) 10(3) New Criminal Law Review 342, 354-360; and Marcia Baron, 'Self Defence: The Imminence Requirement' in Leslie Green and Brian Leiter (eds), Oxford Studies in Philosophy of Law: Volume 1 (OUP 2011), 256. 
The exact specification of both the extent of MLF and the exceptions to it, are matters of political philosophy that I cannot address here. For expositional convenience, in this paper I will assume a view of MLF couched in such broad terms as to hopefully be acceptable to most readers with a liberal view of the state. On this view, MLF is as extensive as is permitted in a rule of law state. It extends to all uses of force that are identified as being presumptively criminal. Hence, it includes force used in self-defence, as well as force used under duress. Private access to force is permitted only exceptionally. When the state permits private access to force, it grants a person limited access to its own power to use force. The state may delegate as much power to intervene as it has - thereby allowing the individual to 'stand in' for the state ${ }^{8}$ - or any lesser amount. However, it cannot permit a private actor to use force that it was not itself authorised to use. Hence if, in a given situation, the state's own power to use force is constrained by principles of moral and political philosophy, it cannot permit anyone deriving authority from itself to exercise that power free of the same constraints. If the state would, for whatever reason, not have intervened forcefully, then no private individual (including the holder of an entitlement under threat) can legitimately ${ }^{9}$ use force either. I do not assert that these assumptions are either empirically correct, or necessitated by philosophical principle. They are merely plausible stipulations that I use for the purposes of this study.

One philosophical challenge to this sketch of MLF that I want to briefly mention draws from Hobbesian theory. It is sometimes argued that the right to defend one's life and bodily integrity is an inalienable natural right ${ }^{10}$ which cannot be relinquished even when granting the state MLF. Hence

\footnotetext{
${ }^{8}$ See for instance Malcolm Thorburn, 'Justifications, Powers, and Authority' (2008) 117 Yale Law Journal 1070, 1126-8; Victoria F Nourse, 'Reconceptualizing Criminal Law Defenses' (2003) 151 University of Pennsylvania Law Review 1691, 1713, 1725; Youngjae Lee, 'The Defense of Necessity and Powers of the Government' (2009) 3(2) Criminal Law and Philosophy 133, 142-4; Kimberley Kessler Ferzan, 'Self-Defense and the State' (2008) 5 Ohio State Journal of Criminal Law 449, 476-8; Fletcher (n1) at 867. See also $R$ v Jones [2007] 1 AC 136 at 174-6.

9 Though in principle, a person illegitimately using force may be excused from criminal liability. 
MLF does not extend to force used in self-defence, and individuals are simply not answerable to the state in respect of actions taken in defence of life and bodily integrity. A study of the merits of this proposition is beyond the remit of this paper, but even assuming it was correct, the state could monopolise all other presumptively criminal force, such that the legitimate use of private force to defend entitlements other than life and bodily integrity would still derive from the state. Therefore, a reader with the Hobbesian (or similar) objection to my stipulation of MLF may simply read down and re-frame my argument in terms of threats to entitlements other than life or bodily integrity. I have considerable sympathy for the Hobbesian objection, but in this paper, for simplicity, I proceed on the basis that the Hobbesian objection does not constrain the extent of MLF.

In a state that claims the MLF I have described, an individual may not ordinarily use force in justified private defence against threats to her entitlements. She may only do so if there is no nonforceful way to dispel the threat. I will call this general precondition for legitimate access to private force the 'REQUIREMENT' consideration. Uncontroversially, one possible alternative to the private use of force is to invite the state to deal with the threat (where this is a viable option), since the primary responsibility of protecting the subjects' entitlements against criminal threats rests with the state. There may be others. REQUIREMENT ensures that private force is not used when there are alternative ways of safeguarding the interest threatened.

Even when legitimate access to private force is available in principle, since the agent derives her use of force from the state, she may not use force that is unavailable to the state. I call this precondition for the legitimacy of private force the 'Derivative Force' consideration. Within this consideration, we can identify at least two separate limiting principles at work. These are

\footnotetext{
Hobbesian Right of Self-Defense' (2008) 36(6) Political Theory 781, 792-7; David B Kopel et.al., 'The Human Right of Self-Defense' (2008) 22 BYU Journal of Public Law 43. See also George P Fletcher, 'Domination in the Theory of Justification and Excuse' (1996) 57 University of Pittsburgh Law Review 553, 570. For Fletcher, private individuals simply do not cede a total monopoly of force to the state - they reserve the right to use force to secure their own safety against aggression when the danger is imminent and unavoidable. Hence, in emergencies, private individuals use force as principals in their own right, and not as agents of the state.
} 
a. PARSIMONIOUSNESS ${ }^{11}$ : only the minimum effective force must be used; and

b. NON-DISPROPORTIONALITY: the defensive force must not be of disproportionately greater magnitude than the threat.

Note that both PARSIMONIOUSNESS and NON-DISPROPORTIONALITY also apply to the state when $i$ is the instrumentality using force to ward off the threat to D. ${ }^{12}$ PARSIMONIOUSNESS limits the force deployed to the minimum amount necessary to mount an effective defence, thereby ensuring that the rights of individuals (including the aggressor) are afforded appropriate respect. When force is being used privately, PARSIMONIOUSNESS also minimises the scope of the exception to MLF. NON-DISPROPORTIONALITY ensures that the force used to repel a threat does not itself generate inequity. Unsurprisingly, these Derivative Force constraints address concerns that seem more apposite when defining state policy than when guiding individual decision-making.

\footnotetext{
${ }^{11}$ I borrow this term from punishment theory. See generally Norval Morris, 'The Future of Imprisonment: Toward a Punitive Philosophy' (1974) 72(6) Michigan Law Review 1161, 1162-4. The concept to which it refers is well established in the context of defensive force as well. See Fletcher (n1) at 870.

${ }^{12}$ I deliberately avoid the terminology used in much of the extant academic discourse on this subject. Usually, the terms used are 'necessity' and 'proportionality'. In this context, 'necessity' generally includes the conditions that I call 'REQUIREMENT' and 'PARSIMONIOUSNESS'; and 'proportionality' refers to what I call 'NONDISPROPORTIONATENON-DISPROPORTIONALITY'. See for instance Andrew Ashworth, 'Self-defence and the Right to Life' (1975) 34 Cambridge Law Journal 282 at 284-5; Kremnitzer (n1) at 178-9; Boaz Sangero, Self-Defence in Criminal Law (Hart 2006) at 144, 151-2. See also Seth Lazar, 'Necessity in Self-Defense and War' (2012) 40(1) Philosophy \& Public Affairs 3, who seems to include PARSIMONIOUSNESS (at 5) as well as some elements of NONDISPROPORTIONALITY (at 5-6) in his understanding of necessity. These theorists do not object to the use of defensive force that is disproportionately less than the threat faced - their objection is to excessive defensive force. I think the term 'NON-DISPROPORTIONALITY' better conveys that idea. The different terminologies used refer to exactly the same overall set of ideas. However, I believe that the manner in which the ideas have been apportioned between 'necessity' and 'proportionality' in extant academic discourse is potentially misleading, because it obscures some conceptual connections between the applicable principles.
} 
REQUIREMENT then encapsulates the necessary and sufficient conditions for the private actor's in-principle access to legitimate force, whereas the Derivative Force consideration limits the amount of force that may be ceded to a private actor with in-principle access to it, and the manner in which it may be deployed. Any (non-posited) rule that limits a private individual's access to legitimate force or her subsequent deployment of it, slots into one of these two categories, and between them, these two categories exhaust all the principled preconditions ${ }^{13}$ for the permissible private use of force.

As I mentioned previously, each state may adopt its own unique stipulation of MLF. Therefore, one explanation for the difference between the rules applicable in states with the 'stand your ground' view and states that require retreat before the use of force may be that they stipulate MLF differently, with the former set claiming either a narrower domain of MLF, or being more willing to delegate the authority to use force. Such altered stipulations of MLF may be surprising, but they are certainly possible. However, I am more interested in examining whether, in a state with the more typical liberal stipulation of MLF described above, any rule on retreat flows from principle. Accordingly future references to MLF will relate to a stipulation of the nature described

\footnotetext{
${ }^{13}$ Some writers argue for additional determinative factors relating to how the threat arose. Specifically, they argue that D's access to legitimate force is subject to additional conditions (not compatible with the REQUIREMENT and Derivative Force considerations) if either (a) D herself creates the threat situation, or (b) if the person threatening D is acts innocently or is not a morally responsible agent. See for instance Sangero (n12) at 203-4; Ashworth (n12) at 300-1; Fletcher (n1) at 865. I doubt the correctness of (a). This argument usually relies on some theory of forfeiture of rights, and the problems of the forfeiture theory are well catalogued. See for instance Sanford H Kadish, 'Respect for Life and Regard for Rights in the Criminal Law' (1976) 64(4) California Law Review 871, 883-4; Jeremy Horder, 'Redrawing the Boundaries of Self-Defence' (1995) 58(3) Modern Law Review 431, 437-8; and Tziporah Kasachkoff, 'Killing in Self-Defense: An Unquestionable or Problematic Defense?' (1998) 17(5/6) Law and Philosophy 509, 515-9. The intuitions accommodated by condition (a) can be sated by letting D attract independent criminal liability for her fault for creating the threat situation (as well as for any morally intrinsic consequences). As to (b), I will argue in Section 4 that the apparent culpability of the person authoring the threat does have some limited relevance, but only in a manner that is compatible with REQUIREMENT and the Derivative Force considerations.
} 
above.

In a state that claims MLF, D cannot rely upon the justification of private defence if she used force that was not required, or did not satisfy the Derivative Force consideration. Compare this with what we generally call the 'duty to retreat'. When D uses defensive force against a threat instead of retreating, jurisdictions that expect retreat will deny her a justification defence to the charge resulting from her use of force. It seems plausible to suppose then that retreat, should it be mandated, is a condition going either to the agent's in-principle access to force, or to the manner in which she is permitted to deploy force to which she has in-principle access. This means that what is usually referred to as the 'duty to retreat' is not a Hohfeldian duty ${ }^{14}$ at all. In fact, no jurisdiction imposes an imperative duty to retreat upon its subjects - states requiring retreat merely withhold a justificatory defence to the charge presumptively arising from the agent's use of defensive force. ${ }^{15}$ Although this technical observation is important to the argument that follows, I will continue to use the term 'duty to retreat' here, because it is a familiar way to refer to the guidance favouring retreat.

\section{The Substantive Interests in Play}

In the previous section, I stated that an individual may only use force to defend against threats to 'entitlements'. Therefore, before attempting to identify the rules governing permissible private defence, we need some sense of which entitlements may, in principle, be privately defended. It is undisputed that the standard set of personal and property claim-rights is privately defensible. However some theorists also treat additional claims as being amenable to private defence. In this

\footnotetext{
${ }^{14}$ At various points in this piece I will employ the taxonomy of jural relations developed by Hohfeld. Refer in this regard to Wesley Newcomb Hohfeld, Fundamental Legal Conceptions as Applied in Judicial Reasoning and Other Legal Essays (Yale University Press 1919).

${ }^{15}$ Sangero (n12) at 195 notes this, but dismisses it as being insignificant, because he says that attacked people rarely opt to suffer the attack instead of retreating.
} 
section, I consider some of the more controversial additions proposed, and examine whether they should be privately defensible.

\section{A. Hohfeldian Liberties}

Uncontroversially, we can privately defend Hohfeldian claim-rights and Hohfeldian powers. But can we also defend our Hohfeldian liberties? Some writers think so. ${ }^{16}$ Conceptually, Hohfeldian liberties are merely absences of constraint - they are norm vacuums rather than entitlements. It seems strange to suggest that an individual can legitimately demand and receive state permission to use force to defend a norm vacuum. In fact, recognising an entitlement to defend a Hohfeldian liberty would change its nature from a Hohfeldian liberty to a Hohfeldian right or power. Yet norm vacuums continue to exist, and so by definition, they must not be legitimately defensible. I therefore argue that D cannot use force to defend against a threat to her Hohfeldian liberty. Furthermore, when D's Hohfeldian liberty is one of many interests threatened, it adds no weight in determining how much force might be permissible.

Quong disagrees, at least in the context of D's exercise of the Hohfeldian liberty to occupy the space one happens to be occupying. He says that even if $\mathrm{D}$ has no positive normative claim to occupy a particular space, once she does occupy it, she gets at least a prima facie claim to remain in it. ${ }^{17} \mathrm{He}$ gives the example of Albert and Betty who are sitting in a public park, such that Betty's spot gives her the best view of the lake. Albert would like to take Betty's spot, but Quong argues that even if Albert could move Betty without touching or otherwise harming or offending her, he may not. This suggests to him that Betty must have a presumptive claim-right to her location even though she is in a public park. This example is problematic for two reasons. Firstly, it is difficult to

\footnotetext{
${ }^{16}$ See for instance, Jonathan Quong, 'Killing in Self-Defense' (2009) 119(3) Ethics 507, 528-9. See also Sangero (n12), at 194, who treats any threat to D's freedom of action, whether that freedom be a right, a power or a liberty, as amenable to private protection.

${ }^{17}$ Quong (n16) at 528-9.
} 
imagine any scenario in which Albert could move Betty without touching, or harming, or offending, or tricking her, and in all those cases, the normative work is done by Betty's claim-right against being touched, harmed, offended, or tricked. Secondly, even if one assumes that the example is plausible, it does not establish that moving Betty would wrong her (and therefore that she must have some claim-right, which is violated). It does suggest that Albert would commit a wrong by moving Betty, but this wrong may well be a victimless wrong. The state often makes rules that perform coordination functions, and persons violating these rules may diffusely affect the overall system without wronging any particular individual. Such violators commit wrongs without violating any individuals' claim-rights. A jaywalker on a deserted street commits such a wrong. She commits the same wrong even when some individual - say a driver who has to slow down because of her jaywalking - feels particularly aggrieved. It is strange to say that the aggrieved driver had a claimright not to have had to slow down. Equally, it is strange to say that Betty has a claim-right to remain in her spot. A wrong does not always imply the existence of an individual with a claim-right. The various other intuitions that Quong explains on the basis of his theoretical claim-right to the space one occupies ${ }^{18}$ can similarly be explained either by reference to more established claim-rights (such as rights relating to property or the body), or wrongs relatable to co-ordination rules. Therefore, insofar as Quong took on the burden of establishing, by a process of elimination, the existence of a general claim-right to the space one occupies, he fails - he is unable to eliminate these alternative explanations for the intuitions he defends. Indeed, these alternative explanations are far more plausible, since they accord with more established theoretical conceptions of a Hohfeldian liberty.

\section{B. The Social-Legal Order}

One might now argue that the entire set of legal rules, including co-ordination rules, cumulatively set up a social-legal order, which contributes to a general sense of security and predictability.

\footnotetext{
${ }^{18}$ Quong (n16) at 526-37.
} 
Individuals rely on the continuance of this social-legal order when making ordinary decisions like when to cross the street, or where to park. Although the state is entrusted with maintaining this social-legal order, it does so for the benefit of its subjects, who retain a beneficial interest in its maintenance. When T culpably threatens to commit a wrong, she also threatens the social-legal order, thereby threatening the subjects' private interest in the maintenance of the social-legal order. Surely this private interest in the maintenance of the social-legal order is amenable to private defence, using force if required ${ }^{19}$ Or in more practical terms, when $\mathrm{T}$ tries to jaywalk, surely it should be a reason in favour of $\mathrm{D}$ using force to stop $\mathrm{T}$ that we do not want inconsiderate jaywalkers to get their way, by superseding the social-legal order we are guaranteed?

This is an interesting proposition, and there is some truth in it. But if a person acting in legitimate private defence of the social-legal order is justified and not excused, then she must act non-criminally and within the scope of her authority. That view is difficult to reconcile with the widespread consensus that the maintenance of the social-legal order is, at least in the first instance, not the individual's, but the state's responsibility. ${ }^{20}$ Private individuals do not have any general ex ante authority to maintain the social-legal order. In fact, modern states characterise private persons who take it upon themselves to do so as vigilantes, not upstanding citizens. ${ }^{21}$ True, many states

\footnotetext{
${ }^{19}$ See for instance, Sangero (n12) at 67-8. Sangero argues that the widespread existence of the defence of prevention of crime is evidence that the protection of the social-legal order is an independent reason for the state to delegate force. For him, a person using defensive force against a culpable aggressor performs a 'policing action', because 'if the police were present at the time of the event, they would [also] have acted [in the same] way". Moreover, according to him, the use of defensive force in these circumstances deters offenders, prevents offences, and reassures subjects. See also Kremnitzer (n1) at 182-3, 189-96.

${ }^{20}$ Sangero (n12) at 212 acknowledges this and therefore downplays the importance of this consideration, at least in his textual discussion.

${ }^{21}$ See in this context the judgment of the House of Lords in $R v$ Jones (Margaret) [2007] 1 AC 136 at 176, which explicitly clarified that although the Criminal Law Act 1967, s3 appears to be a vigilante's charter (it allows a person to use reasonable force to prevent a crime or arrest offenders or suspected offenders), it is not; and that vigilantism is not to be tolerated:
} 
accept that when the state is unavailable, an individual may take steps to maintain the social-legal order, and accordingly, they grant citizens some powers to make arrests, and offer a defence of prevention of crime. However, these states invariably restrict these concessions such that they are only available in response to culpable threats to core or foundational elements of the social-legal order. For instance, S.3 of the Criminal Law Act 1967 allows an individual to use reasonable force to effect or assist an arrest, or to prevent crime, but S.24A of the Police and Criminal Evidence Act 1984, limits the exercise of this power of arrest to indictable offences. Hence, at least in the context of citizens' arrests, the state recognises a private interest in maintaining the social-legal order only when more serious (and therefore indictable) crimes are in issue. The 'indictable crimes' restriction may be seen as a device to identify crimes that threaten core elements of the social-legal order. Although no similar statutory restrictions explicitly limit the use of force in preventing crime, this power flows from the same underlying interest in maintaining the social-legal order as the power to make a citizen's arrest. Therefore, it would be entirely appropriate for the English courts to adopt a similarly narrow view of the kinds of threats to the social-legal order that generate the in-principle entitlement to use force to prevent crime, and given their conservative attitude towards the prevention of crime defence, ${ }^{22}$ this seems very probable indeed. Illustratively, it seems unlikely that the courts will hold that the interest in maintaining the social-legal order justifies the use of any private force whatsoever to prevent minor and non-victimising offences like speeding down an

"The right of the citizen to use force on his own initiative is... more circumscribed when he is not defending his own person or property but simply wishes to see the law enforced in the interests of the community at large. The law will not tolerate vigilantes. If the citizen cannot get the courts to order the law enforcement authorities to act.... then he must use democratic methods to persuade the government or legislature to intervene."

${ }^{22}$ As evidenced by the aforementioned judgment in $R v$ Jones (Margaret) [2007] 1 AC 136 and in cases like $R v$ Attwater [2010] EWCA Crim 2399 and $R$ v Jackson (Kenneth) [1985] RTR 257, where the courts took a restrictive view of when certain driving offences were completed, such that the defence of prevention of crime was rendered unavailable to persons who intervened thereafter to apprehend the errant drivers. 
empty road, or crossing a red light at a deserted intersection, or parking offences. ${ }^{23}$

If this objection holds water, then any unqualified acceptance of the private defensibility of the social-legal order is suspect. Even though citizens retain an interest in maintaining the sociallegal order, that interest is not coextensive with that of the state. When the state is unavailable, individuals may use force to protect some elements of the social-legal order, but only once some threshold of seriousness has been crossed. In modern states, this threshold of seriousness is crossed by threats to core or foundational elements of the social-legal order, and only these are privately defensible. Or in simpler terms, it is not a good reason for D to privately use force, that we do not want jaywalkers to get their way, because making sure that jaywalkers do not get their way is simply not D's business - it is the business of the state. D should instead invoke state enforcement where possible, or alternatively, rely on the state to punish D for jaywalking. The same will not apply when T's threat is to a core element of the social-legal order - say if T culpably attempts to physically assault $\mathrm{D}$. In that case, amongst the various interests that $\mathrm{D}$ is entitled to protect, will be D's interest in the maintenance of the social-legal order.

\section{Honour}

Another consideration often treated as being, in principle, defensible through the private use of force is D's 'honour'. Although the term 'honour' invites comparison to exalted principles like human dignity, it is important to note that in this context, it refers to nothing more than a supposed entitlement to save face by not having to appear cowardly (either to others or to oneself) when attacked. Now if the state posits an entitlement to honour, then like any other entitlement, it is in principle, privately defensible. A more interesting question is whether there exists any general nonposited entitlement to honour. For some authors, the answer is self-evidently yes. ${ }^{24}$ Similarly, the

\footnotetext{
${ }^{23}$ Witness for instance, the recent banning under the Protection of Freedoms Act 2012, s54 of the practice of private individuals clamping the wheels of vehicles parked without permission on private land in England and Wales.

${ }^{24}$ See Kremnitzer (n1) at 188; Sangero (n12) at 123-4, 194-6.
} 
rhetoric used to justify 'stand your ground' rules in the (primarily American) jurisdictions that have them, treats an entitlement to honour as self-evident. For 'a true man who is without fault', the argument goes, retreat in the face of an assault is 'odious to the American ego', amounts to 'cowardice', ${ }^{25}$ and should not be required by the law. Assuming that these jurisdictions also claim MLF as stipulated here, they would appear to recognise a natural entitlement to honour. So, in these jurisdictions, if T assaults D, T simultaneously threatens D's person and her honour. By dodging T's blows, D can avoid the threat to her person, but not to her honour. D can only defend her honour by standing and fighting, and many 'stand your ground' jurisdictions apparently consider the use even of lethal force entirely appropriate for defending one's honour.

The liveliness of the debate on stand your ground laws suggests that the existence of this supposed general, non-posited entitlement to not appear cowardly is not universally self-evident, and apart from rhetorical invocations of one's ego, no argument for any such entitlement emerges from 'stand your ground' jurisdictions. Thankfully, not everyone has that sort of ego to massage. Even if an entitlement to 'honour' did exist, it is difficult to believe that one could use force, especially lethal force, to defend it.

However, Statman offers an argument for precisely that - a general non-posited entitlement to honour that may be defended using lethal force - on the basis of his 'success condition'. Statman argues convincingly that PARSIMONIOUSNESS implies that defensive force can only be used if it has some prospect of success. Translated into the terms used in this paper, Statman's argument is that D may not use defensive force if she cannot thereby avert the threat, because in those circumstances the defensive force would be a futile additional breach of MLF. But then we need to explain our intuitive belief that when D's life is unjustly threatened by several attackers, she is

\footnotetext{
${ }^{25}$ Michelle Jaffe, 'Up in Arms over Florida's New “Stand your Ground” Law' (2005) 30 Nova Law Review 155, 160161; Annie Wells, 'Home on the Gun Range' (2008) 56 Kansas Law Review 983, 988; P Luevonda Ross, 'The Transmogrification of Self-Defense by National Rifle Association-Inspired Statutes' (2007) 35(1) Southern University Law Review 1, 10-12; Onder Bakircioglu, 'The contours of the right to self-defence' (2008) 72 Journal of Criminal Law $131,154$.
} 
entitled to use lethal defensive force against as many of the attackers as possible, even if she is so outnumbered that she has no realistic prospect of thereby saving her life. ${ }^{26}$ To this end, Statman tentatively suggests that the proposition that force - even lethal force - can be used to defend one's honour, is the most plausible (though not flawless) explanation for our intuitive belief.

One response to Statman is that for someone with the Hobbesian objection to the stipulation of MLF adopted herein, Statman's scenario poses no difficulty - D may use defensive force in these circumstances because her life is under threat, and her right to defend her life and bodily integrity, being an inalienable natural right, is not derived from the state. Being outside the ambit of MLF, it is not limited by the success condition. To include those with the Hobbesian objection in the discussion of Statman's argument, I will recast Statman's puzzle in terms not involving threats to life and bodily integrity. This has the added advantage of making it plausible to think of the person using defensive force in a lost cause being made to stand trial for her actions.

Imagine that T has appropriated D's laptop and is about to escape in his (T's) car by driving through a gated exit. $\mathrm{D}$ is at the gate, but knows that T's car is travelling so fast that even if D shuts the gate, it will burst through and escape, although its headlights and bumper will be damaged in the process. Is D permitted to shut the gate? Statman says that we would intuitively think so. I accept that most people would think it unlikely that D would be punished for shutting the gate. However, for many people, this intuition is attributable, at least in part, to how unlikely it is that $\mathrm{T}$ (or an

\footnotetext{
${ }^{26}$ Daniel Statman, 'On the Success Condition for Legitimate Self-defense' (2008) 118 Ethics 659. Statman also suggests the example of $\mathrm{D}$, who can use lethal force against only two of a group of five persons bent on raping her, although this would not dissuade the others (at 664). Statman says that in this case the success condition should require that $\mathrm{D}$ not use force, since it would not save her from being raped. This example is problematic. The use of lethal force will probably reduce the number of instances of rape, and the number of people that rape D. To that extent, D's use of defensive force would succeed in averting some of the threats she faces. It would be an implausible iteration of the success condition that requires $\mathrm{D}$ to submit to multiple instances of rape because she cannot avoid being raped at least once. See also in this context David Rodin, 'Justifying Harm' (2011) 122(1) Ethics 74, 92-93. Therefore, I ignore this example, and focus on Statman's stronger examples.
} 
observer) would complain to the police about the damage to $T^{\prime} s$ car on these facts. Others might reach the same conclusion because they believe that even if $\mathrm{D}$ was tried for damaging T's car, she would be excused from punishment. But when we excuse $\mathrm{D}$, we do not accept that she acted permissibly, and therefore we do not support the conclusion that Statman draws. Of course, some might still believe that $\mathrm{D}$ is actually permitted to slam the gate shut, but I doubt that the intuitive support for that proposition is anywhere near as pervasive as Statman seems to think it is. Because I deny that the state authorises the private use of force for extracting vengeance, I see no reason why it should authorise D to slam the gate shut on these facts (although it might still excuse D for having done so). On this view, Statman's puzzle disappears, and there is no need to posit a contrived solution depending on the existence of a general entitlement to honour.

All in all, the normative case for treating honour as being amenable to private forceful defence remains unconvincing. Ashworth's contention that the use of defensive force against a threat that can be averted by retreat is illegitimate, even if retreat involves some loss of face, ${ }^{27}$ remains the more plausible position.

\section{Approaches to Theorising Retreat and Submission}

Having examined the sorts of entitlements that are privately defensible, we can now begin to consider the rules governing permissible private defensive force. The principle traditionally identified as the basis for the 'duty to retreat' is necessity. ${ }^{28}$ The term 'necessity' has been used in academic discourse to refer collectively to the constraints on the legitimate access to force that I call

\footnotetext{
${ }^{27}$ Ashworth (n12) at 290, 303.

${ }^{28}$ Joseph H Beale, 'Retreat From a Murderous Assault' (1903) 16 Harvard Law Review 567, 572-4; Ashworth (n12) at 284, 293; Andrew Ashworth, Principles of Criminal Law (OUP 2009) at 120-4; Fiona Leverick, 'Defending SelfDefence' (2007) 27 OJLS 563, 576-7; Fiona Leverick, Killing in Self-Defence (OUP 2006) at 69-86; Sangero (n12) at 193; Fletcher (n1) at 867; Model Penal Code $\$ 3.04(2)(b)(i i)$. Note that necessity in this context is different from necessity as a defence in its own right.
} 
REQUIREMENT and PARSIMONIOUSNESS. ${ }^{29}$ In summary, the argument from necessity is as follows: force may be used in private defence if it is necessary and proportionate in the circumstances. One of the ways in which a contemplated use of force can be unnecessary is if the threat can be averted by non-violent means such as retreat. ${ }^{30} \mathrm{I}$ will argue that while this description of the 'duty to retreat' is not incorrect, it can be further refined. But first, it will be instructive to consider as a counterpoint, what a model of retreat based on NON-DISPROPORTIONALITY might look like.

Sangero offers such a model. ${ }^{31} \mathrm{He}$ draws up two tables in which he compares, first the interests at stake in cases in which safe retreat is possible, and second, the interests at stake in cases

\footnotetext{
${ }^{29}$ For instance, see Ashworth (n12) at 284-5; Kremnitzer (n1) at 178-9; Sangero (n12) at 144, 151-2. Clubbing REQUIREMENT and PARSIMONIOUSNESS together has its appeal. Just as we may dub the use of force unnecessary if a threat can be averted by seeking state protection or by retreat, we may dub the use of a specified amount of force unnecessary if less force would have repelled the threat. But it may be that because the word 'necessary' (along with its variants) is flexible enough to apply to both these cases, valuable distinctions between these cases have been overlooked.
}

${ }^{30}$ Ashworth (n12) at 284-5. See also Sangero (n12) at 193-4 who recounts the orthodox argument. Note that because of the extended scope of 'necessity' as used in the orthodox argument, we can also say that force exceeding the minimum effective force is not necessary force.

${ }^{31}$ Sangero (n12) at 192-217. Sangero adopts this approach because of two flaws that he perceives in necessity-based models of retreat, viz. that they lead to the intuitively anomalous conclusion that $\mathrm{D}$ must retreat from $\mathrm{T}$ if $\mathrm{T}$ intends to kill D, but may hold her ground and use defensive force - even deadly force - if T intends to rob D [see for instance Beale (n28) at 572-4]; and, that they cannot explain why retreat is not required as an alternative to the use of moderate defensive force, despite a general consensus to that effect [see for instance A P Simester and others, Simester and Sullivan's Criminal Law (5 ${ }^{\text {th }}$ edn, Hart 2013) at 786-8]. Most credible necessity-based models of retreat address Sangero's first concern by incorporating a subsequent NON-DISPROPORTIONALITY analysis as an additional constraint on how much force can be used even when retreat is unnecessary [see for instance Ashworth (n12) at 293303; Leverick, Killing (n28) at 69-86; Leverick, 'Defending' (n28) at 575-7; Fletcher (n1) at 867]. Sangero's second objection is flawed. It wrongly assumes that the consensus that retreat is not required as an alternative to the use of moderate defensive force is based on underlying philosophical principles. More on this in Section 4A. 
in which safe retreat is impossible. When retreat is impossible, considerations such as the life (or where the threat is of injury, the interest in not being injured) of the person attacked, and a series of secondary factors, favour the use of defensive force. These are balanced against the attacker's life (or where the defensive force needed is non-lethal, the attacker's interest in not being injured), and potentially, some secondary factors. Where retreat is possible, in the set of the factors favouring the use of force, the attacked person's life/interest in not being injured is replaced by her interest in not being in danger, and her honour. Using these tables and the proportionality calculation that they represent, Sangero reaches conclusions about when the use of defensive force is appropriate. In particular, he concludes that retreat may not be required even when it is possible. ${ }^{32}$

I am interested in the table relating to defensive force when retreat is possible. The fundamental flaw in Sangero's model is laid bare in this statement that he makes:

My opinion is that despite the possibility of safe retreat, defensive force is necessary, and ... the requirement of necessity is actually fulfilled. However, although the interests necessitating defence do not include the life of the person attacked and his bodily integrity - since these can be saved by means of a retreat - they do include less central interests: the defence of the social-legal order, the freedom of action of the attacked person, and his honour. Consequently, the real question is no longer a question of necessity, but rather a question of proportionality: whether the use of deadly defensive force for the defence of the social-legal order, freedom of action of the attacked person and his honour meet the conditions of the proportionality requirement. ${ }^{33}$ [Emphasis supplied]

Let us say that T's attack is primarily directed at a set of D's entitlements - ' $\alpha$ '. In the extract above, for Sangero, $\alpha$ is D's life or bodily integrity. Sangero takes himself to be explaining the scope of D's 'duty to retreat' from a threat to $\alpha$. However, where safe retreat from a threat to $\alpha$ is possible, he excludes $\alpha$ from the proportionality calculation altogether. ${ }^{34}$ Instead, he identifies 'less central'

\footnotetext{
${ }^{32}$ Sangero $(n 12)$ at $208-15$.

${ }^{33}$ Sangero (n12) at 194.

${ }^{34}$ Sangero might respond that the identity of the entitlement denoted by $\alpha$ continues to influence the magnitude of T's threat to the D's honour and the social legal order. However, as I have argued, his inclusion of factors like honour and
} 
interests like "the defence of the social-legal order, the freedom of action of the attacked person, and his honour" as weighing in favour of D's claim to use defensive force. Let us refer to these less central interests collectively as $\beta$. The interests clubbed together as $\beta$ are such that by definition they cannot be protected by retreat. Effectively, Sangero asserts that $\mathrm{D}$ is also entitled to $\beta$, and that $\beta$ is also being threatened by $\mathrm{T}$. He then considers whether there is any proportionate defensive response available to D to protect $\beta$, failing which, $\mathrm{D}$ is directed to retreat. However, if measures not disproportionate to the threat to $\beta$ can be used to avert the threat to $\beta$, then $\mathrm{D}$ can stand her ground and employ those measures, despite the possibility of retreat from the threat to $\alpha$. This is all very well, but it is misleading to describe this analysis as an analysis of the duty to retreat from a threat to $\alpha$, and it is misleading to describe the guidance to D last recounted as guidance that it is unnecessary to retreat from a threat to $\alpha$. By taking $\alpha$ out of the proportionality calculus, Sangero all but concedes that there is a 'duty to retreat' from a threat to $\alpha$ because its defence does not require the use of force, while arguing that nevertheless, since $\beta$ cannot be protected by retreat, force is required to protect $\beta$. He then considers what force would be proportionate (or, in the terminology used here, NON-DISPROPORTIONATE) for defending $\beta$. Ultimately therefore, even for Sangero, the 'duty to retreat' depends on whether the use of force is required to protect either $\alpha$ or $\beta$, and since $\beta$ is defined such that it cannot be protected by retreat, force is always required to protect it. It only remains to determine how much defensive force would be NON-DISPROPORTIONATE while defending $\beta$. Where there is no NON-DISPROPORTIONATE defensive response to a threat to $\beta,{ }^{35}$ Sangero's advice to D is more accurately described as "submit ${ }^{36}$ to the loss of $\beta$ (and invoke state mechanisms for later redress)", than "retreat from the threat to $\alpha$ ". When a NON-

\footnotetext{
the social legal order in the proportionality calculus is itself questionable.

${ }^{35}$ Sangero does contemplate such situations. See case 3 in his Table 2(B) in Sangero (n12) at 208-9, and also his discussion of what is, essentially, the 'duty to submit' (at 215-7).

${ }^{36}$ It is important to remember that like the 'duty to retreat', the guidance in favour of submitting does not impose a Hohfeldian duty. It merely reminds that when even the most PARSIMONIOUS effective defensive force is disproportionate to the threat to $\beta$, no force can justifiedly be used.
} 
DISPROPORTIONATE defensive response to a threat to $\beta$ is available, Sangero's advice to D is more accurately stated as "you may stand your ground and defend yourself against the threat to $\beta$ ", than "you may stand your ground and defend yourself against the threat to $\alpha$ (or, $\alpha$ and $\beta$ )".

Sangero's model of pure retreat (excluding submission) then converges with Ashworth's necessity-based description of retreat. ${ }^{37}$ Ashworth recognises that only part of what he calls the necessity condition - the part that I call REQUIREMENT - is sufficient to explain the 'duty to retreat', but does not analyse that part separately. In this paper, I examine the constraints on private force set by REQUIREMENT separately from those set by PARSIMONIOUSNESS, and group PARSIMONIOUSNESS with NON-DISPROPORTIONALITY to consider the constraints that they impose.

\section{A. REQUIREMENT and the 'Duty to Retreat'}

We start with REQUIREMENT. Although Sangero's analysis is flawed, it is useful. His errors demonstrate the importance of distinguishing between the preconditions for in-principle access to force, and the constraints upon the manner in which force can be deployed after obtaining inprinciple access to it. Conditions comprising the Derivative Force consideration are, in principle, also applicable to the state in its use of force; not so conditions comprising REQUIREMENT. This is why it is plausible to argue that neither the state, nor an individual, is permitted to use disproportionate or excessive force to quell a threat. By contrast, when faced with a threat to a subject's entitlement, the state is not required to retreat, ${ }^{38}$ although the subject concerned might be. Since the 'duty to retreat' does not (even in principle) apply equally to the state and the individual, it must flow from REQUIREMENT, and not from the Derivative Force consideration. Unreflectively, Sangero applies this very idea in excluding the weight of entitlements that can be protected by

\footnotetext{
${ }^{37}$ Ashworth (n12) at 284-5.

${ }^{38}$ At least, not for reasons to do with MLF. It is nevertheless possible that retreat may be required in special cases for reasons of state policy.
} 
retreat from his proportionality analysis. My own conception of the rule on retreat, which flows straightforwardly from the same idea, is this: an entitlement that can be protected by seeking state protection or by retreat contributes no weight to a claim to stand one's ground. Along similar lines, a threat to a core element of the social-legal order that can be averted or reduced to a threat to a noncore element of the social-legal order without the private use of force, also contributes no weight to a claim to stand one's ground. Jurisdictions requiring retreat interpret REQUIREMENT such that it is not satisfied when the threat may be neutralised through state intervention, or by non-forceful means, such as retreat.

But on this model, exactly when is REQUIREMENT satisfied? Is it when the materialisation of the threat is immediate, or when it is unavoidable? To explain the sense in which I employ these terms, let me use a non-legal analogy. When games between excellent chess players end decisively, they often end with one player resigning rather than being checkmated. In situations like these, the defeated player (let's call her Karpova) resigns because she sees an unavoidable checkmate several moves down the line. She may realise for instance, that her opponent has commenced an attack in which (if her opponent plays wisely) she will checkmate Karpova in five moves. Karpova believes that her opponent is good enough to see this sequence of moves, and so decides that since the checkmate is unavoidable, she might as well resign. Alternatively Karpova may play on in the hope that her opponent will blunder. In that case, it is only when her opponent reaches out to move the piece that delivers the coup de grâce that checkmate is immediate. If resigning in chess is seen as an (admittedly strained) metaphor for getting in-principle access to defensive force, then should the state allow Karpova to resign as soon as she sees an unavoidable checkmate, or should it insist that she wait until checkmate is immediate?

Sangero argues for a scalar version of immediacy, in which the more immediate the materialisation of the threat becomes, the more defensive force is available. This is because he collapses the preconditions for access to force and its deployment into a single proportionality 
analysis, in which the interests of both the defender and the attacker carry weight. ${ }^{39}$ Sangero's loyalties therefore veer away from unavoidability (which facilitates earlier access to force, and therefore, less protection for the attacker) and towards immediacy (which delays access to force, thereby giving additional protection to the attacker). Leverick argues for a different concept, closer to unavoidability, ${ }^{40}$ but glosses over the fact that this substantially differs from immediacy, either as Sangero uses the term, ${ }^{41}$ or as I do. Many other writers have weighed into this debate, using different terminology, or the same terminology in slightly different senses. ${ }^{42}$ As we have already seen, the rule on retreat in England and Wales seems to follow Sangero's model, relating D's access to force to the immediacy of the materialisation of the threat, but treating this immediacy as a scalar factor in a reasonability analysis. ${ }^{43}$ Scotland on the other hand, insists on immediacy per se, inasmuch as it requires D to exhaust all reasonable avenues of retreat that do not enhance the risk she faces, or prejudice the effectiveness of her defensive options. ${ }^{44}$

To identify what it takes to cross the REQUIREMENT threshold, we need to identify the baseline situation that we would like the exception to MLF to restore. We know that this baseline is disturbed when $\mathrm{D}$ faces a threat. This suggests that D's baseline is the complete freedom from threats to herself or her entitlements. When T alters D's baseline situation by authoring a threat to D, D may use force, if required, to return to her baseline threat-free situation. D's use of force is

\footnotetext{
${ }^{39}$ Sangero (n12) at 150-2, 155-6, 160-2. See also Leverick, Killing (n28) at 101, who traces the argument for imminence/immediacy to concern for the aggressor's rights, which are best protected by giving unpredictable chance factors like unforeseen interruptions or changes of heart, as much time as possible to end the threat without force.

${ }^{40}$ Leverick, Killing (n28) at 101-2.

${ }^{41}$ Leverick, 'Defending' (n28) at 579.

${ }^{42}$ See for instance Kimberley Kessler Ferzan, 'Defending Imminence: From Battered Women to Iraq' (2004) 46 Arizona Law Review 213; Joshua Dressler, 'Battered Women Who Kill Their Sleeping Tormentors' in Stephen Shute and A P Simester (eds), Criminal Law Theory: Doctrines of the General Part (OUP 2002) 259; and Baron (n7) at 228. ${ }^{43}(\mathrm{n} 2)$. ${ }^{44}(\mathrm{n} 3)$
} 
required when there is no (non-forceful) way to completely nullify the threat, inasmuch as state protection is unavailable, and retreat is either impossible, or will not nullify, but only postpone the materialisation of the threat. ${ }^{45}$ In other words, force is required when a threat is present, and without force, its materialisation would be unavoidable. Thus unavoidability satisfies the REQUIREMENT threshold, and there is no need to wait for the materialisation of the threat to also become immediate before $\mathrm{D}$ is allowed in-principle access to force. This is the position I adopt on the exact specification of the REQUIREMENT threshold for my model of the 'duty to retreat'.

Note that this standard imports two distinct prerequisites for crossing the REQUIREMENT threshold: first, the threat must be a present one; and second, its materialisation must be unavoidable (though not necessarily immediate). The former prerequisite has been largely neglected in academic discourse, which has instead focussed on whether defensive force may be used when it gives $\mathrm{D}$ the best chance of averting an anticipated harm, ${ }^{46}$ or only when $\mathrm{T}$ has unambiguously begun to perform the action that will harm $\mathrm{D} .{ }^{47}$ These two positions do not exhaust the possibilities. I will argue that it is possible (i) for a threat to present before $\mathrm{T}$ begins to perform the action that will actually harm D; and (ii) for D's best chance of averting the anticipated harm to arise before there is a present threat of harm. ${ }^{48}$ In terms of the present threat prerequisite of the unavoidability standard,

\footnotetext{
45 To clarify, when I talk about the materialisation of a threat, I refer not only to situations in which harm is actually caused, but also to situations in which T succeeds in exposing D to an illegitimate risk of harm. Hence when T aims a gun with one bullet in it at D and pulls the trigger with neither party knowing whether the bullet is chambered, the threat to D has materialised whether or not the bullet was in fact chambered.

${ }^{46}$ Paul H Robinson, Criminal Law Defenses Volume 2 (West Publishing Co. 1984) at 78. See also Ferzan (n42) at 241-2, who recounts and critiques such an approach.

${ }^{47}$ Dressler (n42) at 272-5.

${ }^{48}$ Consider the famous Supreme Court of North Carolina case of State v Norman 378 SE2d 8. Here D had suffered almost 25 years of terrible physical and mental abuse from her husband T. She was too scared to press charges against $\mathrm{T}$ or leave him because whenever she had tried, $\mathrm{T}$ had retaliated violently. $\mathrm{T}$ had also repeatedly threatened to kill her and members of her family. One evening, when T had fallen into a drunken sleep after another session of violent abuse, D took a gun from her mother's house and shot T dead. Some commentators suggest that on these facts, D seized her best
} 
the use of defensive force would potentially be permitted in (i), but not (ii), ${ }^{49}$ because in (i) a present threat has altered D's baseline position whereas in (ii), D's baseline situation has not yet been disturbed.

The adoption of the unavoidability standard then requires us to distinguish between an impending threat on the one hand, and a present threat, the materialisation of which is unavoidable but not yet immediate, on the other. Because the baseline situation is disturbed only when $\mathrm{D}$ faces a present threat, she has grounds to seek access to force only in response to a present threat, and not in response to an impending, but not present, threat. To some extent, the practical determination of when this threshold has been crossed will be a matter of judgment, with marginal cases being difficult to classify. Conceptually however, a bright line separates a present threat from a future threat, and important consequences relating to the availability of defensive force turn on this distinction. Although I do not propose to suggest tests for making this distinction here - that would probably require another paper ${ }^{50}-\mathrm{I}$ am confident that the 'in-principle' distinction can be made, just

chance to save herself from T's violence and impending deadly assault, because she would have been powerless to defend herself against $\mathrm{T}$ when $\mathrm{T}$ was actually attacking her. Assuming that to be correct, D's best chance of averting the anticipated harm would arise before there was any present threat of harm. See in this connection Kaufman (n7) at 346-8.

${ }^{49}$ Ferzan (n42) at 257-62, presents an argument along these lines, using different terminology. She argues that the imminence/immediacy condition has conceptual purchase independently of its usefulness as evidence of the necessity of defensive force - it restricts the legitimate use of force to responses to aggressions. In effect, she changes the imminence/immediacy condition to an aggression condition. See in this connection Baron (n7) at 254-5. I do not adopt Ferzan's 'aggression' proposal because it requires T to be culpable, and I think that D may also legitimately use defensive force against $\mathrm{T}$ when $\mathrm{T}$ authors a threat non-culpably. Thus, whether $\mathrm{T}$ is an infant who does not realise the significance of her actions, or a clumsy person who stumbles and falls towards D, she may be treated as authoring a threat against D, and D may, subject to other conditions, use defensive force against $\mathrm{T}$. Note also that nothing in the assertion that $\mathrm{D}$ should not use force before she faces a present threat, requires that she not be excused from criminal liability if she did use such force.

${ }^{50}$ See Ferzan (n42) at 257-62 for one attempt along similar lines, with the slightly different concept of aggression. Ferzan uses the idea of aggression to cover almost, but not quite, the same ground as my 'present threat'. She also agrees 
as we can distinguish between merely preparatory acts and attempts. Certainly core instances of impending threats are easily distinguishable from core instances of present threats, the materialisation of which are unavoidable, but not yet immediate. So, if T, a racist, phones up D, a black person, and tells D that she (T) is coming to the market, where D currently is, to kill D, T's threat to D's life is impending, but not present. At this stage D is not pushed to respond to T's threat in any way, including by going home to forestall it, even if she would have no choice but to use lethal force to defend herself once T reached the market. ${ }^{51}$ On the other hand, when T starts aiming blows at $\mathrm{D}$, the threat is a present one even if $\mathrm{D}$ knows that she can duck at least the first few (or even all of the) blows aimed by T. At this stage, D is pushed to respond to T's threat, and if her contemplated response includes the use of force, she may be required to first consider retreat.

This view of the 'duty to retreat' as flowing from REQUIREMENT suggests that the distinction often made between the rule on retreat as applicable to cases calling for lethal defensive force, and other cases, ${ }^{52}$ has no philosophical basis. Philosophically, the 'duty to retreat' depends solely on whether there is any way to avert the threat without using any private force at all. Only if that is impossible (and therefore retreat is not required) do we consider the severity of the most PARSIMONIOUS effective defensive response to the threat. Hence, when deciding whether retreat is required, it makes no difference whether the most PARSIMONIOUS effective defensive response to the threat involves lethal or non-lethal force. Once it is established that retreat is not required, the determination of the amount of force permitted is (in philosophical principle) simply a question of proportionality, and the same general rules apply in all cases. Obviously, these rules would require a much higher threshold of proportionality to be met in order to justify the use of lethal force.

that "[p]revention cannot be justified as [self-defence]", and therefore would also disallow the use of force to prevent an anticipated threat from being posed.

${ }^{51}$ But see Larry Alexander, 'Propter Honoris Respectum: A Unified Excuse of Preemptive Self-Protection' (2005) 74

Notre Dame Law Review 1475, 1479-80, who argues that D should go home because taking a life is not a proportional response to the threat to a few minutes of liberty at the marketplace, even if it is proportional to a threat to D's life.

${ }^{52}$ Sangero (n12) at 198-202; Simester and others (n31) at 786-8. 
Therefore, any distinction between the rule on retreat applicable to cases calling for lethal defensive force and other cases, is best explained on doctrinal, rather than philosophical, bases.

Note that this analysis focuses entirely on the rights of $\mathrm{D}$, and not at all on the rights of $\mathrm{T}$. This is entirely appropriate. At the REQUIREMENT threshold, there is no reason to insist that D be concerned with the rights of anyone else, since crossing that threshold creates only in-principle access to force. D only affects the rights of others when she actually deploys that force, and only at that stage should she have to consider the rights of T. At that stage, because D's access to force is derived from the state, it is subject to the limitations that apply to the state. Those limitations are encapsulated in the Derivative Force consideration. ${ }^{53}$

\section{B. Derivative Force and the 'Duty to submit'}

Passing the REQUIREMENT threshold does not authorise D to use as much force as she wants to defend her entitlements. Since the individual's authority to use force derives from the state, at most she may use as much force as the state could have used. This Derivative Force consideration includes constraints such as PARSIMONIOUSNESS and NON-DISPROPORTIONALITY. Of these, PARSIMONIOUSNESS is relatively straightforward and uncontroversial. Only defensive options that use the minimal force necessary for repelling the attack are even potentially permissible. ${ }^{54}$ Hardly anyone argues that a person may, in self-defence, use more force than would be adequate to repel the attack, even if such force would nevertheless not be disproportionate to the

\footnotetext{
${ }^{53}$ This is why I think that both Sangero (n12) at 161 and Leverick, Killing (n28) at 76; 'Defending' (n28) at 575-6 err in considering the aggressor's rights at the REQUIREMENT stage. If my analysis is correct, then there is no good reason to require $\mathrm{D}$ to extend the time for which she must suffer a present and operating threat. T's interests are irrelevant when considering the REQUIREMENT threshold, and so D does not have to safeguard them by indulging the speculative possibility that T might suddenly decide to desist, or a deus ex machina may intervene.

${ }^{54}$ Fletcher (n1) at 870. See also Sangero (n12) at 207-9.
} 
threat posed by the attack. ${ }^{55}$

A more contested constraint is NON-DISPROPORTIONALITY. I will not attempt to suggest any formula for the actual disproportionality calculus here - despite attempts to do so by others, I doubt that this calculus is reducible to formulaic guidance. Nor will I debate the epistemic variables that must be factored into the proportionality calculus. Instead, assuming epistemic perfection, I use a series of hypotheticals to build on the arguments made in Section 3 and describe what I believe are the minimal contours of a 'duty to submit'. This 'duty to submit' may be made more onerous by a state which legislates to further limit the amount force it delegates to an individual, but it cannot be relaxed without becoming inconsistent with MLF. In each of the scenarios that follow, I assume that state protection is unavailable, and that all parties are fully aware of all relevant facts.

In Case 1, D has parked in T's favourite, but not proprietary or officially designated, parking space. She is still in the driver's seat with the engine on, when T threatens to throw a stone at the car unless D moves. D can avoid the stone in one of only two ways: she can drive out of the way of the stone (thereby vacating the parking space); or she can put a bullet through T's throwing hand before T releases the stone. On the model proposed, since D can avert T's threat without resorting to force by driving out of the parking space (i.e. retreating), the REQUIREMENT threshold for the use of force to protect D's car is not crossed. Assuming that there are no other entitlements in play, D is not authorised to use any force against $\mathrm{T}$ whatsoever. Her best option would be to retreat, and let T's comeuppance take the form of state sanction for her attempt or threat to damage D's car.

\footnotetext{
${ }^{55}$ Since we are identifying the ideal parameters of the proportionality calculus, let us assume that the actor perceives the 'true' facts. The only writer who suggests that the deliberate use of non-PARSIMONIOUS force is justifiable is Larry Alexander, 'Lesser Evils: A Closer Look at the Paradigmatic Justification' (2005) 24 Law and Philosophy 611, 618-200. That flows from his thoroughgoing commitment to consequentialism, which though internally consistent, generates conclusions that would strike many as implausible. That said, I cannot offer a knock-down argument about why his thoroughgoing commitment to consequentialism is inappropriate, and so I will not try to convince people who share Alexander's starting point, and his intuitions.
} 
An obvious question arises: Doesn't guiding D to move her car make a mockery of D's freedom to park in that space? I think it does not, partly because D's freedom to park in the space is a mere Hohfeldian liberty which cannot be privately defended, and partly because the guidance offered is not imperative guidance. ${ }^{56}$ Despite the 'duty to retreat', D retains her Hohfeldian liberty to stand her ground. Doing so would not expose her to criminal liability. She would not however be permitted to shoot at T's hand to defend her car against the threat posed by $\mathrm{T}$, and she might face criminal liability if she did so. Yet, if T did damage D's car, T could be held criminally responsible for that.

Notice that the 'guidance' offered in Case 1 to $\mathrm{D}$ is not that she should avoid parking in the space; it is that she should avoid the stone by vacating the space. The former guidance would have been imperative guidance telling her not to so something that she was normatively unrestrained from doing. Of course the state has the power to give such guidance, but if it did so because of T's illegitimate threat, it would effectively be legitimising T's threat. That would be inappropriate. ${ }^{57}$ On the other hand, telling D that her only justified defensive response to T's threat is to move her car out of the parking space is perfectly legitimate, even though $\mathrm{D}$ is under no normative restraint against remaining in the space, and even though in a perfect world doing so would not require her to choose between suffering damage to her car or prosecution for shooting T. When D chooses to take any defensive measure, she abandons several alternative courses of action on which she could have embarked without legal censure. Most of the unrestricted courses of action available to us are mutually exclusive, and the mere fact that the law does not intervene to neutralise a factor that makes choosing one of them less attractive does not make the law's 'guidance' illegitimate.

Now consider Case 2. Here, T warns D that she will damage D's car if she parks in a

\footnotetext{
${ }^{56}$ Sangero (n12) at 195, noticed the latter factor, but failed to appreciate its significance.

${ }^{57}$ But see Alexander (n51) at 1479-80 who differs. In my opinion, a theory that recognises that retreat is a condition for private access to force rather than an imperative duty will accept that until a threat is present, D cannot seek private access to force, and so cannot be put to the condition of retreat for access to it.
} 
specified space. In Variation 1, this space is simply an empty patch of unclaimed land. In

Variation 2, the space is a designated parking space in a public parking lot. What conduct guidance in respect of the use of force would be available to $\mathrm{D}$ if she wanted to park in the specified space despite T's warning in both alternative variations?

In both variations, T's threat to D's Hohfeldian right or entitlement (her car) is contingent upon D exercising her freedom to park in the specified space. Prior to doing so, since no threat to her car has fructified, D cannot justifiably use force to defend her car. Now in Variation 1, the space is merely an unclaimed patch of land. Both $\mathrm{T}$ and $\mathrm{D}$ are free to park their respective cars in that space (or to use it as they please), but neither is entitled to park there. T and D enjoy only Hohfeldian liberties to park in the space. Since D has no entitlement to remain unrestrained from parking in the specified space, she cannot legitimately use force to protect her claim to park there. D would therefore be advised not to use force to protect her freedom to park in the specified space, and instead to refer the matter to the state authorities. Of course, in the absence of any legitimate imperative guidance against parking in that space, D may, without fear of legal censure, park there anyway. Should T then threaten D's car, D would have to examine the options in the manner described for Case 1.

In Variation 2, both $\mathrm{T}$ and $\mathrm{D}$ are free to park their respective cars in the identified space, but this time, their respective freedoms are also backed by an additional posited right to park there (conditional on the space being vacant, and on the payment of a fee). Both have a conditional Hohfeldian right to park in the space, but no right to restrain each other from parking there should the other meet the conditions. When the state posits a special provision for an individual or section of the public, it can be understood to implicitly also empower the beneficiaries of this provision to protect it within the constraints of the law - it would be redundant to authoritatively reiterate the lack of authoritative guidance against doing something. T's warning then constitutes a threat to D's conditional entitlement to park in the space, and if there is no way to avert this threat (say by convincing $\mathrm{T}$ to withdraw the threat) or to avail of state protection, the use of force may be required 
to protect D's entitlement to park there. Of course, D would still have to ensure that the force she uses satisfies both the PARSIMONIOUSNESS and NON-DISPROPORTIONALITY constraints. In this case, the interests threatened would be D's claim to park in the specified space (and not her Hohfeldian right to her car). This remains the case even if D actually parks in the space (assuming of course that D could still protect her car by moving it). ${ }^{58}$ One might argue that T's warning, given that it is culpable, constitutes a threat to D's interests in the maintenance of the social-legal order, and so this should also carry some weight in determining the maximum amount of defensive force that would not be disproportionate. However, it seems unlikely that any state would treat a threat to a person's in-principle access to a parking space as the sort of threat to her interest in the sociallegal order that she can repel using force. In other words, it is unlikely that a state would see T's threatened conduct as a threat to a core element of the social-legal order.

Ashworth argues that where there is some time between D becoming aware of a future threat and the threat actually presenting itself, D ought to seek police protection or inform the police of the impending threat, failing which her use of defensive force would be tainted. This, Ashworth argues, would reduce the need for the private use of force ${ }^{59}$ Undoubtedly, it would. However, this condition does not flow from any of the constraints on the private use of force, because none of them become applicable until an individual actually needs private access to force, i.e. until the threat actually presents itself. They are not imposed as part of a system of measures calculated to minimise the need for private recourse to force. Such a system already exists - it is the legal system in general. Nothing in MLF ipso facto requires an individual to take steps to pre-empt threats from presenting themselves - whether they be avoiding 'dangerous' places, or not wearing 'provocative clothes', or

\footnotetext{
${ }^{58}$ Such a variation would be Case 1 , except that the parking space would be a designated space in a public lot. D would then be entitled to remain in place and use force not disproportionate to the threat to her entitlement to park there (not the threat to her car), to defend that entitlement. So while D might be permitted to tickle T (if that would avert the threat), she would probably not be permitted to punch T. If D has no effective NON-DISPROPORTIONATE response available, her most favourable legal option is to protect her car by vacating the space.

${ }^{59}$ Ashworth (n12) at 295-6. C.f. Alexander (n51) at 1479-80, who recommends retreat in such cases.
} 
informing the police of anticipated threats. Of course, it might still be wise and useful for people to inform the police about anticipated threats, and it is perfectly competent for the state to enact the rule that Ashworth suggests. However, this rule is not a part of the general 'duty to retreat', and in the absence of any expressly posited rule to that effect, the failure to take such pre-emptive action should not defeat a person's subsequent claim to justification in using defensive force.

Now consider a different example. In Case 3, D is standing ten feet from the edge of a cliff. T picks up a stone to throw at $\mathrm{D}$. If the stone hits $\mathrm{D}$, it will inflict minor injury. $\mathrm{D}$ can avoid being hit in one of two ways: she can sidestep the stone by moving one foot closer to the edge; or she can pre-emptively throw a stone at T's hand, thereby injuring $\mathrm{T}$ and preventing her from throwing the stone. To avoid cluttering up the argument with too many variables, let us assume that neither T's threat to D's entitlement to remain in place, nor her entitlement to avoid being hurt, constitutes a threat to a core element of the social-legal order. ${ }^{60}$ In Variation 1, T has only one stone. In Variation 2, T has eleven stones, and $\mathrm{D}$ does not have the option of retracing her steps after moving.

In Variation 1, as is clear from the foregoing discussion, my opinion is that the only noncriminal way in which D can avoid being hit by the stone is to move one foot closer to the cliff. Some commentators rely on the Divisional Court decision in Redmond-Bate v. DPP 61 to suggest

\footnotetext{
${ }^{60}$ The assumption that T's threat to D's claim to remain in place does not threaten a core element of the social-legal order is admittedly more plausible than a similar assumption in respect of D's entitlement to avoid being hurt. If either of these assumptions were rejected, then D's corresponding interest in the maintenance of core elements of the sociallegal order would weigh into the Derivative Force analysis for determining the outer limit of NONDISPROPORTIONATE defensive force.

${ }^{61}$ [2000] HRLR 249. The appellant, a Christian fundamentalist, was preaching from the steps of a cathedral. A crowd of about a hundred people, some hostile, gathered. Fearing a breach of the peace, a policeman asked the women to stop preaching. She refused, and was arrested for, and convicted of, wilfully obstructing the police officer in the execution of his duty. Her conviction was set aside on the grounds that the policeman had no right to call upon the appellant to desist from lawful conduct, unless it gave rise to a reasonable apprehension that it would provoke violence by interfering with the rights and liberties of others.
} 
that in English doctrine there is no duty to retreat from the scene, if one's presence is lawful and if the defensive force is non-fatal. ${ }^{62}$ This is a misreading of the case. Redmond-Bate did not involve the evaluation of a claim to justification by an actor who could have averted a threat by retreat but instead chose to maintain her lawful presence and take more serious defensive measures. The court was actually asked to consider whether the appellant's Hohfeldian liberty (or arguably even Hohfeldian right, given that she had, in advance, agreed her course of conduct with the police) to preach from the steps of a cathedral could legitimately have been curtailed because of the likelihood that her continued exercise of it would provoke an illegitimate response from an angry mob that had gathered to berate her. It was, in effect, the same question as in Case 2 Variation 1 discussed above, and the court reached the same conclusion. The fact that in Redmond-Bate the appellant was already present at the cathedral, whereas in Case 2 Variation 1, D is not yet present in the parking space does not effectively distinguish the two cases. In both cases, the question is, "Is it legitimate to constrain a person's Hohfeldian liberty in response to an illegitimate threat?", and the answer is 'No'. ${ }^{63}$ Redmond-Bate does not support the proposition for which it has been cited, and that proposition is unsound both doctrinally and philosophically.

Now consider Variation 2. What steps would D be justified in adopting to avoid being hit? Assuming that doing so does not increase the danger faced by D or prejudice the effectiveness of her defensive option, must D move towards the cliff for as long as she can without going over the edge and only then throw her own stone at T's hand, or can she throw her stone immediately? To require D to sidestep the stones for as long as possible might arguably provide added insurance against any misperception by D of the situational facts, including T's intentions. It might also allow $\mathrm{T}$ to voluntarily cease her attack, or allow for some unforeseen intervention - say $\mathrm{T}$ being unnerved

\footnotetext{
${ }^{62}$ Simester and others (n31) at 787.

${ }^{63}$ See in this connection Ashworth (n12) at 295-6. See also $R v$ Field [1972] CrimLR 435, in which an appellant who was warned that some persons were coming to attack him, stood his ground instead of fleeing. During the ensuing attack, the appellant used lethal force to defend himself against one of his attackers. The Court of Appeal set aside his conviction, holding that the fact that he had stood his ground did not disentitle him from using force to defend himself.
} 
by the siren of a passing ambulance - to cause the attack to cease without the need for force. This question goes to the heart of whether the Scottish rule requiring retreat-until-cornered is based on philosophical principle.

The answer, I would suggest, has to do firstly with D's subjective perception of the threat, and secondly with D's duties (if any) towards T. Let us consider first how D honestly perceived the threat to herself. Did she (Situation 1) believe that T would keep throwing stones until D could no longer avoid them without falling over the cliff? Or did she think that T would stop short of doing that (Situation 2)? If she thought the latter, then any claim that D might make to legitimately use force to avoid being hit by the stone(s) would fall at the REQUIREMENT threshold. Hence the only appropriate defensive response for $\mathrm{D}$ would be to sidestep the stone. She must do this for as long as she continues to believe that $\mathrm{T}$ will not simply force her over the edge of the cliff. If, after a few such side-steps, $\mathrm{D}$ comes to believe that $\mathrm{T}$ is not going to stop until $\mathrm{D}$ cannot sidestep the stones any more, then Situation 2 merges into Situation 1.

What then is the conduct guidance available to D in Situation 1? The state may of course posit an express retreat-until-cornered condition for legitimate private access to the use of force for prudential reasons, in which case the question posed is straightforwardly answered. However, where no such stipulation exists, the only source of any guidance to retreat comes from REQUIREMENT, which is satisfied by unavoidable, rather than immediate, threats. If $\mathrm{D}$ believes that $\mathrm{T}$ will keep throwing stones until $\mathrm{T}$ hits $\mathrm{D}$, then $\mathrm{D}$ is faced with a present and unavoidable threat, and not a contingent threat. Sidestepping the first stone will not avert the threat - it will merely postpone it without affecting its unavoidability. Since it is impossible to avert the threat by means other than injuring T's hand, the REQUIREMENT threshold for the D's use of force is crossed. D is not required to retreat or delay her response, and may legitimately defend herself using force that satisfies the PARSIMONIOUSNESS and NON-DISPROPORTIONALITY constraints.

In examining whether D's most PARSIMONIOUS defensive option is a NONDISPROPORTIONATE response, it is important to correctly quantify the variables in play. Here, D 
is faced with the choice of either submitting to injury by stoning, or dying by falling off a cliff. D can reduce the magnitude of the threat she faces by choosing to avoid the more serious threat - the threat to her life. In effect, she can 'retreat' from the threat to her life, albeit by choosing a course of action that involves facing the lesser threat of injury by stoning. Hence the only inevitable and unavoidable threat that $\mathrm{D}$ faces from $\mathrm{T}$ is the threat of injury by stoning. Her response must be proportionate to that threat. One might still argue that the amount of defensive force that would be appropriate should depend on whether $\mathrm{D}$ thinks that $\mathrm{T}$ will try to hit $\mathrm{D}$ as many times as possible, or just once. If $\mathrm{D}$ believes the former, then she can respond with more force than if she believes the latter. I disagree. This proposition clandestinely reintroduces the assumption that $\mathrm{D}$ is entitled to stand her ground, when (on the facts stated) all D has is an unrestricted freedom to stand her ground. Since there is no legal entitlement, D is not entitled to stand her ground (although she would incur no blame if she just stood her ground). If D retreats until it is no longer safe to retreat, she will be hit by one stone. ${ }^{64}$ Therefore, if $\mathrm{D}$ chooses to stand her ground despite having an avenue of safe retreat, the escalation in the scale of the threat she faces is attributable to D's own choice. ${ }^{65}$ The unavoidable threat that $\mathrm{D}$ faces is only the threat of injury by being struck by one stone, and her response must not in any case be disproportionate to that unavoidable threat. In summary, in Case 3 Variation 2 Situation 1, D can use defensive force immediately, without having to sidestep any stones, or to wait until she at the edge of the cliff. However, the defensive force that she takes must be PARSIMONIOUS and must not be disproportionate to the amount of unavoidable threat she faces - the threat of being hit by one stone. If there is no NON-DISPROPORTIONATE yet effective response available to $\mathrm{D}$, then she cannot legitimately take any defensive action. Her best (legitimate) course of action would be to sidestep the stones for as long as it is safe to do so, and then to suffer minor injury by stoning. She would have to rely on the criminal law to subsequently

\footnotetext{
${ }^{64}$ I assume here that D can retreat to the edge of the cliff without a heightened perception of the risk to herself.

${ }^{65}$ Though again, if $\mathrm{T}$ hits $\mathrm{D}$ multiple times, T remains criminally responsible to the state for the harm actually caused to D by the multiple strikes. Nevertheless, in the model I propose, the extent of D's criminal responsibility is not relevant for determining the amount of defensive force that would be permissible.
} 
punish T, and perhaps claim compensation from T under civil law. D could also legitimately stand her ground and risk greater injury. If as a result $\mathrm{T}$ injured $\mathrm{D}$ more severely, $\mathrm{T}$ would face greater consequences under both criminal and civil law. ${ }^{66}$

We can now consider a case that is usually treated as meriting special normative treatment calling for either an exception to the rule on retreat, or allowing for a greater amount of legitimate defensive force, viz. an attack by T on D in D's home (or similar place of refuge). ${ }^{67} \mathrm{I}$ think that the intuitive plausibility of such special treatment derives from the fact that $\mathrm{D}$ has a posited entitlement to remain in her dwelling, as opposed to her mere Hohfeldian liberty to remain in a public place. Furthermore, this entitlement is generally thought to be particularly strong ${ }^{68}-$ stronger than, say, the entitlement to park in a public car-park. A threat to D's person that can be averted only by retreat from her home therefore also constitutes an independent threat to her entitlement to remain in her home. If state protection against this second threat is unavailable, and it cannot be averted without force, the REQUIREMENT threshold is crossed, and force may, in principle, be used to neutralise it. Although D may still only use force that satisfies the Derivative Force consideration, because the entitlement to remain in one's home is particularly strong, a NON-DISPROPORTIONATE response to a threat to it might involve much more force than a similarly qualified response to a threat to one's entitlement to park in a public car-park. Therefore although the same rules apply to cases in

\footnotetext{
${ }^{66}$ In reality, the proportionality calculus is (and must inevitably be) much more rough and ready than this, in order to take into account the psychological stresses faced by D in an emergency situation. The hypothetical example described in the main text should therefore be understood as an exercise in philosophical norm clarification, rather than as a practical demonstration of how the courts should determine the proportionality of D's defensive response.

${ }^{67}$ See for instance Ashworth (n12) at 294; Fletcher (n1) at 868; and Sangero (n12) at 266-8. Sangero argues that greater defensive force is permissible in response to an attack in a dwelling place, and the Model Penal Code drops the requirement of retreat in respect of such attacks altogether. See Model Penal Code, §3.04(2)(b)(II)(1). C.f. Leverick, Killing (n28) at 84-5; 'Defending' (n28) at 577 who denies that this is a special case.

${ }^{68}$ See for instance Ashworth (n12) at 294. Many explanations have been offered for this. Fletcher (n1) at 868 and Sangero (n12) at 266-8 suggest that humans naturally relate to the dwelling place in a special manner, as an expression of their autonomy. Leverick, Killing (n28) at 83 says that this simply a matter of sentiment.
} 
which a person may only escape an attack by retreating from her dwelling place, the special nature of the posited entitlement to remain in one's home explains why retreat from the home is considered a special case.

A final clarification is called for at this stage. The foregoing discussion on the 'duty to retreat' and the 'duty to submit' has focussed solely on the ex ante guidance that $\mathrm{D}$ can be given as to what conduct is permissible and justified. But even if she does not follow the guidance discussed herein, D may be excused from criminal liability. I do not consider excuses here, but it remains possible that someone who does not prefer effective retreat to using defensive force, or who uses disproportionate or non-PARSIMONIOUS defensive force instead of submitting to a threat, may be excused from criminal liability.

\section{Conclusion}

An understanding of the proper scope of the 'duties' to retreat and submit is essential in a world in which individual rights are being asserted with increasing combativeness. While there is every reason for the law to come to the aid of a person facing an undeserved threat to her rights, that policy consideration cannot require the state to dilute its monopoly of force to the extent that the state becomes a secondary agent for the ex ante protection (as distinguished from the ex post enforcement) of rights. A state that does so shirks its responsibility to its citizens, even if it does so in response to popular demand. In requiring its subject to retreat from, and occasionally submit to, a threat, the state reinforces its role as the primary protector of the rights of its subjects.

In terms of the theoretical arguments made in this paper, a person should only be permitted to privately use force to protect

(a) interests from the set of privately defensible interests, as qualified in Section 3 above,

(b) after a present threat to them arises, and

(c) when the threat cannot completely be avoided by retreat. 